\title{
The comparison of preemptive analgesic effects of curcumin and diclofenac
}

\author{
Nurullahoglu Atalik KE ${ }^{1}$, Okudan $\mathrm{N}^{2}$, Belviranli $\mathrm{M}^{2}, \mathrm{Oz} \mathrm{M}^{2}$ \\ Necmettin Erbakan University Meram Medicine Faculty Department of Pharmacology, Konya Turkey. \\ esraatalik@hotmail.com
}

\begin{abstract}
Objective: Preemptive analgesia is an antinociceptive treatment that prevents central sensitization. Antinociceptive effects of diclofenac are well-known. The aim of this study was to investigate preemptive analgesic effects of curcumin and diclofenac, before acute and inflammatory induced pain in rat model.

Material and methods: Fourty eight old female ( $n=6$ in each group) Wistar Albino rats were included in the study. Paw movements in response to paw flinching in response to formalin injection or thermal stimulation were compared after curcumin (400 mg kg-1, p.o.) and diclofenac (10 mg kg-1, i.p.) administration. Saline was used as a control. The solvent ethanol was administered in another group of rats. Preemptive analgesic effect was significant in both tests when curcumin and diclofenac was administrated before the pain stimuli.

Results: Oral administration of curcumin and intraperitoneal injection of diclofenac increase the response time in hot plate test and decrease the number of flinches in formalin test $(p<0.001$ vs $p<0.05)$.

Conclusion: These results suggest that curcumin had preemptive analgesic effects on acute thermal, and inflammatory induced pain in rats as diclofenac (Fig. 2, Ref. 35). Text in PDF www.elis.sk.

Key words: curcumin, diclofenac, preemptive analgesic effect, rat.
\end{abstract}

Preemptive analgesia is a treatment that is initiated before and is operational during the surgical procedure in order to reduce the physiological consequences of nociceptive transmission provoked by the procedure. Owing to this 'protective' effect on the nociceptive pathways, preemptive analgesia has the potential to be more effective than a similar analgesic treatment initiated after surgery. Consequently, immediate postoperative pain may be reduced and the development of chronic pain may be prevented $(1,2)$.

Experimental evidence proposes that to 'prevent' or 'preempt' the noxious input to the CNS, may be more

effective than treatment. The idea of preemptive analgesia was first introduced into clinical practice by Crile in 1913 (3) and further developed by Wall (4) and Woolf (5). The definition of preemptive analgesia was formed by Kissin (6). According to him, preemptive analgesia is "treatment that prevents establishment of central sensitization caused by incisional and infl ammatory injuries; it starts before incision and covers both the period of surgery and the initial postoperative period. Preemptive analgesia prevents pathologic pain that is different from physiologic pain", which means: prevention or reversal of central and peripheral sensitization.

Diclofenac sodium, 2-[(2,6-dichlorophenyl) amino] benzene acetic acid, is a non-steroidal anti-inflammatory drug (NSAID)

\footnotetext{
${ }^{1}$ Necmettin Erbakan University Meram Medicine Faculty Department of Pharmacology, Konya Turkey, and ${ }^{2}$ Selcuk University Medicine Faculty Department of Physiology, Konya Turkey
}

Address for correspondence: K.E. Nurullahoglu Atalik, Department of Pharmacology, Faculty of Meram Medicine, University of Necmettin Erbakan, Konya 42080,Turkey.

Fax: +903322237124 with an approximate relative COX-1/COX-2 specificity ratio of one (7). NSAIDs inhibit the cyclo-oxygenase enzymes (COX) and decrease peripheral and central prostaglandin production. To reduce the inflammation that accompanies tissue injury, decreasing prostaglandin production attenuates the response of the peripheral and central components of the nervous system to noxious stimuli and reduces the pain occurring in response to following noxious stimuli (8). These properties would seem to make NSAIDs ideal drugs to use in preemptive approach.

Curcumin (diferuloylmethane) is a yellow-colored phenolic pigment, obtained from powdered rhizome of

Curcuma longa, Linn. family - Zingiberacae. It is the major bioactive constituent of the oleoresin of turmeric.

Turmeric is extensively used as a spice, food preservative and coloring material in India, China and Southeast Asia (9). Curcumin has demonstrated a wide spectrum of therapeutic effects such as anti-inflammatory, antibacterial, antiviral, antifungal, antitumor, antispasmodic and hepatoprotective. Clinically, curcumin has been used to reduce postoperative inflammation (10). Safety evaluation studies indicate that both turmeric and curcumin are well tolerated at high dose ranges without any toxic effects. Thus, both turmeric and curcumin have wide potential in the development of modern medicine for treatment of various diseases (11). In addition, curcumin has been reported to have antinociceptive activity when administered systemically. The analgesic effects of curcumin are thought to be exerted by suppression of nitrite, TNF- $\alpha$, and capsaicininduced TRPV1 activity, and through the descending noradrenergic and serotonergic systems (12-14). Furthermore, curcumin has been shown to exhibit anti-inflammatory activity by means of inhibition of a number of 


\section{$757-760$}

different mediators including phospholipase, lipoxygenase, cyclooxygenase-2, leukotrienes, thromboxane, prostaglandins, and nitric oxide (15-17).

The formalin test is a well-established and frequently used model to study mechanisms of pain. It produces a longlasting noxious input towards the spinal cord and the brain (18). A subcutaneous (s.c.) injection of formalin into the rat hindpaw produces a biphasic excitatory-evoked behavioral response, results in persistent tissue damage, and induces a state with good approximation to some clinical conditions of chronic inflammatory pain. Therefore it is widely used to evaluate inflammatory processes, central sensitization, and different pain-mediating substances.

Preemptive analgesic effect of diclofenac is discussed in many studies, but the results are still controversial (19-21). To date, preemptive analgesic properties of curcumin were not reported in a rat model of both acute and inflammatory pain.

In the present study, the preemptive analgesic properties of systemically administered curcumin and diclofenac were investigated in a rat model of acute and inflammatory pain.

\section{Materials and methods}

\section{Animals and husbandry}

For this study, prior permission for animal experimentation was obtained from the Necmettin Erbakan University Experimental Medicine Research and Application Center Ethics Committee (29 February 2012, No: 2012/25). Fourty eight old female (18 months) Wistar Albino rats, weighing 325-350g were used in this study. All animals were housed in a controlled environment, with free access to food and water and were maintained on a $12 \mathrm{~h} / 12$ $\mathrm{h}$ day/night cycle. Each animal was used only once. Each group consisted of 6 animals.

\section{Formalin test}

The formalin test was carried out as described by Tjolsen et al (18). Rats were given normal saline ( $0.5 \mathrm{ml}$, i.p.), ethanol (5 $\%$, p.o.), curcumin (400 mg kg-1, p.o.), diclofenac (10 $\mathrm{mg} \mathrm{kg}^{-1}$, i.p.) before injecting formalin. Curcumin suspension was prepared in $5 \%$ ethanol solution. Curcumin suspension was freshly prepared and administered orally at the dose of $400 \mathrm{mg} \mathrm{kg}^{-1}$ body weight $45 \mathrm{~min}$ before formalin injection. Diclofenac was given 15 min before formalin injection. The formalin test was performed by subcutaneously injecting $50 \mu \mathrm{L}$ of $1 \%$ formalin solution into the plantar surface of the right hind paw using a 30 gauge needle. The formalin injection evoked a characteristic spontaneous flinching behaviour, and thus the pain behavior was quantified by periodically counting the number of flinches of the injected paw. The number of flinches was counted recorded in $10 \mathrm{~min}$ intervals for $60 \mathrm{~min}$. The observed responses appeared biphasically and were divided into phase $1(0-10 \mathrm{~min})$ and phase 2 (11-60 min).

\section{Hot plate test}

The acute thermal pain was realized by using hot plate apparatus (MAY 9619, Ankara, Turkey). The method of hot plate test

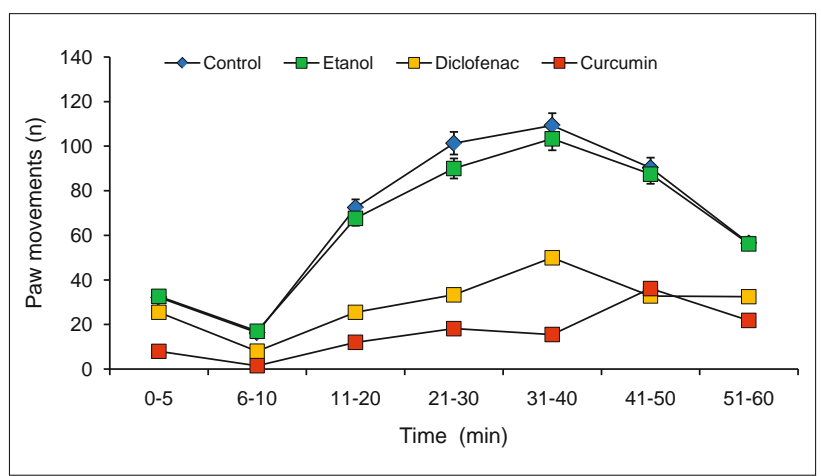

Fig. 1. Paw movements after normal saline (0.5 ml, i.p.), ethanol (5 \%, p.o.), curcumin (400 $\mathrm{mg} \mathrm{kg}^{-1}$, p.o.), diclofenac (10 $\mathrm{mg} \mathrm{kg}^{-1}$, i.p.) before the pain stimuli with formalin test. Data were expressed as means \pm SEM. Six rats in each group.

is an adaptation of that described by Eddy and Leimbach (22). The hot plate test was performed at $55^{\circ} \mathrm{C}$ on the paw of each rat. Animals were placed on the heated smooth surface and the latency of licking, shaking of the limbs or jumping was measured. Rats were given normal saline ( $0.5 \mathrm{ml}$, i.p.), ethanol ( $5 \%$, p.o.), curcu$\min \left(400 \mathrm{mg} \mathrm{kg}^{-1}\right.$, p.o.), diclofenac $\left(10 \mathrm{mg} \mathrm{kg}^{-1}\right.$, i.p.). The reaction time was recorded at $0,15,30,60$ and 90 min after administration of agents. To prevent the tissue injury rats were removed from the hot plate test after $30 \mathrm{sec}$.

Drugs

Diclofenac sodium (Sigma Aldrich, St Louis, MO, USA), Curcumin (Sigma Chemicals, St Louis, MO, USA) were used. Diclofenac sodium was dissolved in normal saline. Curcumin suspension was prepared in $5 \%$ ethanol solution.

\section{Statistical analysis}

Data were expressed as means \pm SEM. Differences among treated groups were statistically evaluated using the ANOVA followed by the Tukey's post-hoc test. Differences were considered significant at $\mathrm{p}<0.05$.

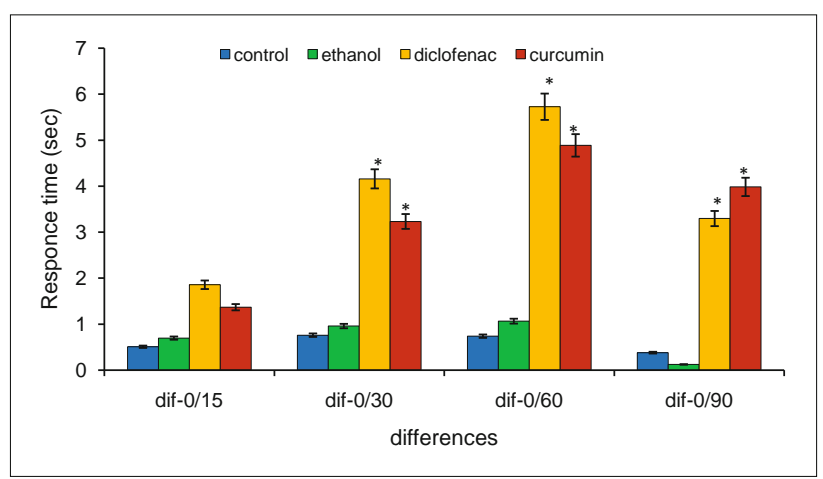

Fig. 2. Hot plate test. Response time in the hot plate test for curcumin and diclofenac with control (saline) and ethanol group. Data were expressed as means \pm SEM. Six rats in each group.* ${ }^{*}<0.001$. 


\section{Results}

Subcutaneous injection of formalin into the hind paw produced a biphasic flinching response, with an early (phase 1) response lasting 5-10 min, and after a quiescent interval of 5-10 min, a subsequent late (phase 2) response up to $60 \mathrm{~min}$. The paw responses observed at 10 minutes intervals during a period of 60 minutes were compared. Figure 1 shows the time course and dose-response data of curcumin and diclofenac administered before formalin injection, in the formalin test. Preemptive analgesic effects of curcumin and diclofenac sodium in formalin test were demonstrated by observation of flinching of paw after formalin injection. Preemptive antinociceptive effects of curcumin and diclofenac administered groups in formalin test were significantly different in both phase 1 and 2, compared with control group and ethanol administered groups $(\mathrm{p}<0.05)$ (Fig. 2). The number of paw flinches was significantly decreased in curcumin administered group compared with diclofenac administered group in phase 1 . In the early part of phase 2 (10-30 $\mathrm{min}$ ), there was no significant difference between the curcumin and diclofenac administered groups. But in $40 \mathrm{~min}$ of phase 2 diclofenac significantly decreased the number of paw flinches compared with curcumin.

Preemptive analgesic effects of curcumin and diclofenac sodium administered in hot plate test were demonstrated by increase in response time compared with control $(p<0.001)$. Diclofenac sodium produced an increase in response time, which was significantly higher than curcumin in 30 and $60 \mathrm{~min}$. However, curcumin administration showed a significant increase in response time in 90 min compared with diclofenac administrated group $(\mathrm{p}<0.001)$.

No analgesic effect was observed in control and ethanol adminstered groups in hot plate tests.

\section{Discussion}

In the recent study, we demonstrated that curcumin and diclofenac sodium had preemptive analgesic effects in formalin test and in the hot plate test in rats. Preemptive analgesia can reduce both the acute and inflammatory pain and in this way can reduce peripheral and central sensitization.

Preemptive analgesic effect was obvious with NSAIDs due to their mode of action, competing with arachidonic acid for binding to cyclooxygenase and decreasing the formation of prostaglandins (23). Treatment with NSAIDs should be started as early as possible and should be initiated before the input of nociceptive stimuli. However, the clinical value of this technique remains still uncertain. Woolf et al (24) showed no difference with preoperative diclofenac from postoperative diclofenac in patients undergoing laparascopic tubal ligation. However, Buggy et al (25) and Gillberg et al (26) demonstrate that preoperative administration of ketorolac, piroxicam and diclofenac did reduce postoperative pain in patients undergoing laparoscopy. Our findings support these results as well. It is expected that NSAIDs will play an increasing role in preemptive analgesia and pain relief in general.

The hot plate test evaluates supraspinal antinociceptive effects, and it reflects activity in thermally sensitive afferent fibers and activity of $\mathrm{A} \delta$ and $\mathrm{C}$ fibers (27). Responses in the formalin test are mediated by both the spinal and supraspinal sites. The phase 1 response of the formalin test is caused by the direct stimulation of nociceptors by formalin or tissue damage, and is thought to be an acute pain reaction. This reflects activity that is prominent in $\mathrm{A} \beta, \mathrm{A} \delta$ and high-threshold $\mathrm{C}$ nociceptor afferent fibers. The phase 2 response is caused by inflammation after formalin injection and central sensitization related to $\mathrm{C}$ activity. It reflects activity in mechanically insensitive afferent fibers and activity of $A \delta$ and $C$ fibers (8). Sensory fibers respond to physical and chemical stimuli producing mediators with origin from tissue injury and inflammation. These inflammatory mediators activate or sensitize afferent fibers, and the neural impulses originated from nociceptors are transmitted via peripheral nerves to the spinal cord and with cranial nerves to cranial nerve ganglia. Prostaglandins are among the most important mediators of inflammatory pain. During inflammation prostaglandin formation is induced by cyclooxygenase (COX) enzymes. NSAIDs block COX enzymes production and produce analgesia (28). Studies have highlighted that NSAIDs do not increase the pain threshold in animal model such as tail-flick and hot plate tests, but they normalize the pain behavior, which is observed after tissue injury and inflammation mechanism $(29,30)$. Antigona et al (31) shows that i.p. administered diclofenac has preemptive and antinociceptive effects in acute thermal and inflammatory induced pain.

In the present study, it was found that curcumin supressed inflammatory pain more potently than diclofenac in the early phase of pain. It was reported that the early phase of formalin pain is a neurogenic pain and produced due to direct activation of $\mathrm{C}$-fiber nociceptors (18). It was reported that anti-inflammatory drugs did not affect the first phase of formalin pain even when a very low formalin concentration was used (32). The role of curcumin in formalin model of plantar pain has been tested in a previous study (33) in which curcumin administered orally failed to reduce the licking and biting behavior in acute phase. Although, it was reported that oral bioavailability of curcumin is very poor (34), in this study we administered it orally as Tajik et al (33) used. These investigators also reported that the antinociceptive effect of curcumin on the inflammatory pain may be related to its antiinflammatory property. It has been reported that curcumin has the ability to inhibit the activation of inflammatory mediators, such as COX 2, lipooxygenase, inducible nitric oxide synthase and nuclear factor kappaB (35). In this study, we observed that curcumin has spinal and supraspinal preemptive analgesic effects as diclofenac. With our data, we can not suggest which mechanisms underlie this effect of curcumin. However, no studies have compared the preemptive analgesic effects of curcumin and diclofenac before.

In conclusion, the present results suggest that in rats both curcumin and diclofenac have preemptive analgesic effects. Further studies must be performed to clarify the mechanism of curcumininduced preemptive analgesic effects.

\section{References}

1. Woolf CJ, Chong MS. Preemptive analgesia-treating postoperative pain by preventing the establishment of central sensitization. Anesth Analg 1993; 77: 362-379. 
$757-760$

2. Kissin I. Preemtive analgesia problems with assessment of clinical significance. Methods Mol Biol 2010; 616: 475-482.

3. Crile GW. The kinetic theory of shock and its prevention through anociassociation. Lancet 1913; 185: 7-16.

4. Wall PD. The prevention of postoperative pain. Pain 1988; 33: 289-290.

5. Woolf CJ. Central mechanisms of acute pain. In: Bond MR, Charlton JE, Woolf CJ (Eds). Proc. 6th World Congress on Pain 1991, Amsterdam: Elsevier, 25-34.

6. Kissin I. Preemptive analgesia. Anesthesiology 2000; 93: 1138-1143.

7. Van der Marel CD, Anderson BJ, Romsing J et al. Diclofenac and metabolite pharmacokinetics in children. Pediatr Anaesth 2004;14: 443-451.

8. KokkiI H. Nonsteroidal anti-infl ammatory drugs for postoperative pain: a focus on children. Pediatr Drugs 2003; 5: 103-123.

9. Chattopadhyay I, Biswas K, Bandyopadhyay U et al. Turmeric and curcumin: Biological actions and medicinal applications. Curr Sci 2004; 87: 44-53.

10. Kohli K, Ali J, Ansari MJ et al. Curcumin: A natural anti-inflammatory agent. Indian J Pharmacol 2005; 37: 141-147.

11. Sharma S, Kulkarni SK, Agrewala JN et al. Curcumin attenuates thermal hyperalgesia in a diabetic mouse model of neuropathic pain. Eur J Pharmacol 2006; 536: 256-261.

12. Yeon KY, Kim SA, Kim YH et al. Curcumin produces an antihyperalgesic effect via antagonism of TRPV1. J. Dent Res 2010; 89: 170-174.

13. Zhao X, Xu Y, Zhao Q et al. Curcumin exerts antinociceptive effects in a mouse model of neuropathic pain: Descending monoamine system and opioid receptors are differentially involved. Neuropharmacology 2012; 62: 843-854.

14. Chainani-Wu N. Safety and anti-inflammatory activity of curcumin: a component of tumeric (Curcuma longa). J Altern Complement Med 2003; 9: 161-168.

15. Banerjee M, Tripathi LM, Srivastava VM et al. Modulation of inflammatory mediators by ibuprofen and curcumin treatment during chronic inflammation in rat. Immunopharmacol. Immunotoxicol 2003; 25: $213-224$.

16. Xu YX, Pindolia KR, Janakiraman $N$ et al. Curcumin inhibits IL1 alpha and TNF-alpha induction of AP-1 and NF-kB DNA-binding activity in bone marrow stromal cells. Hematopathol Mol Hematol 1997-1998; 11: 49-62.

17. Goel A, Boland CR, Chauhan DP Specific inhibition of cyclooxygenase-2 (COX-2) expression by dietary curcumin in HT-29 human colon cancer cells. Cancer Lett 2001; 172: 111-118.

18. Tjolsen A, Berge OG, Hunskaar S et al. The formalin test: an evaluation of the method. Pain 1992; 51: 5-17.

19. Riad W, Moussa A. Preoperative analgesia with rectal diclofenac and/ or paracetamol in children undergoing inguinal hernia repair. Anaesthesia 2007; 62: 1241-1245.
20. Tuzuner AM, Ucok C, Kucukyavuz Z et al. Preoperative diclofenac sodium and tramadol for pain relief after bimaxillary osteotomy. J Oral Maxillofac Surg 2007; 65: 2453-2458.

21. Yukawa $\mathbf{Y}$, Kato F, Ito $\mathrm{K}$ et al. prospective randomized study of preemptive analgesia for postoperative pain in the patients undergoing posterior lumbar interbody fusion continuous subcutaneous morphine, continuous epidural morphine, and diclofenac sodium. Spine 2005; 30: 2357-2361.

22. Eddy NB, Leimbach D. Systemic analgesic: II. Dithienyl-butenyl and dithienylbutylamines. The Journal of Pharmacology and Experimental Therapeutics 1953; 107: 385-393.

23. Mccrory CR, Lindahl SG. Cyclooxygenase inhibition for postoperative analgesia. Anesth Analg 2002; 95: 169-176.

24. Woolf CJ, Chong MS. Preemptive analgesia - treating postoperative pain by preventing the establishment of central sensitization. Anesth Analg 1993; 77: 362-379.

25. Buggy DJ, Walli C, Carton EG. Preoperative or postoperative diclofenac for laparoscopic tubal ligation. Br J Anaesth 1994; 73: 767-770.

26. Gillberg LE, Harsten AS, Stahl LB. Preoperative diclofenac sodium reduces post-laparoscopy pain. Can J Anaesth 1993; 40: 406-408.

27. Espejo EF, Mir D. Structure of the rat's behaviour in the hot plate test. Behav Brain Res 1993; 56: 171-176.

28. Dray A. Inflammatory mediators of pain. Br J Anaesth 1995; 75 : 125-131.

29. Bjorkam R, Hedner J, Hedner T et al. Central, naloxone-reversible antinociception by diclofenac in the rat. Naunyn Schmiedebergs Arch Pharmacol 1990; 342: 171-176.

30. Miranda HF, Lopez J, Sierralta F et al. NSAID antinociception measured in chemical and a thermal assay in mice. Pain Res Manage 2001; 6: 190-196.

31. Antigona SH, Marija S, Jakupi MH et al. Preemptive analgesic effect of diclofenac: Experimental Study in rats. MEJ Anesth 2011;21:355-360.

32. Rosland JH, Tejolsen A, Maehle B et al. The formalin test in miceeffect of formalin concentration. Pain 1990; 42: 235-242.

33. Tajik H, Tamaddonfard E, Hamzeh-Gooshchi N. Interaction between curcumin and opioid system in the formalin test of rats. Pak J Biol Sci 2007; 10: 2583-2586.

34. Yang KY, Lin LC, Tseng TY et al. Oral bioavailability of curcumin in rat and the herbal analysis from Curcuma longa by LC-MS/MS. J. Chromatogr B Analyt Technol.Biomed Life Sci 2007; 15: 183-189.

35. Bengmark S. Curcumin, an atoxic antioxidant and natural NFkappaB, cyclooxygenase-2, lipooxygenase, and inducible nitric oxide synthase inhibitor: a shield against acute and chronic diseases. J Parenter Enteral Nutr 2006; 30: 45-51.

Received June 7, 2013. Accepted August 18, 2014. 